\title{
Anti-p200 Pemphigoid: A Systematic Review
}

\author{
Khalaf Kridin ${ }^{1}$ and A. Razzaque Ahmed ${ }^{2 *}$ \\ ${ }^{1}$ Department of Dermatology, Rambam Health Care Campus, Haifa, Israel, ${ }^{2}$ Department of Dermatology, Center for \\ Blistering Diseases, Tufts University School of Medicine, Boston, MA, United States
}

\section{OPEN ACCESS}

Edited by:

Ralf J. Ludwig,

Universität zu Lübeck, Germany

Reviewed by:

Takashi Hashimoto,

Osaka City University, Japan

Hiroshi Koga,

Kurume University School of

Medicine, Japan

*Correspondence:

A. Razzaque Ahmed arahmedmd@msn.com

Specialty section:

This article was submitted to Autoimmune and Autoinflammatory

Disorders,

a section of the journal

Frontiers in Immunology

Received: 08 August 2019 Accepted: 03 October 2019 Published: 22 October 2019

Citation:

Kridin K and Ahmed AR (2019) Anti-p200 Pemphigoid: A Systematic Review. Front. Immunol. 10:2466. doi: 10.3389/fimmu.2019.02466
The many clinical aspects of anti-p200 pemphigoid are not well-characterized. We aimed to analyze and correlate known existing data on the epidemiological, clinical, histological, and immunological features of anti-p200 pemphigoid. We performed a review using Medline, Embase, and Web of Science databases (1900-2018). Case reports and series of patients were included. A total of 68 eligible studies that comprised 113 anti-p200 pemphigoid patients were included in the qualitative analysis, where there was a mean age of onset of 65.5 years. All patients presented with bullae/vesicles, and $54.3 \%$ had urticarial plaques. A similarity to bullous pemphigoid was reported in $66.1 \%$ of cases, but palmoplantar (51.4\%), cephalic (40.3\%), and mucosal (38.5\%) involvement, besides frequent development of scars/milia (15.7\%), were reported. Autoantibodies against recombinant laminin $\gamma 1$ were detected in the sera of $73.1 \%$ of patients. Psoriasis was present in $28.3 \%$ of anti-p200 pemphigoid patients, particularly among Japanese patients (56.4\%). The incidence of pustular psoriasis in this subgroup, was significantly greater than in the normal population. In conclusion, the diagnosis of anti-p200 pemphigoid may be suspected when a subepidermal autoimmune blistering disease develops in a younger age group, along with significant acral and cephalic distribution and mucosal involvement.

\footnotetext{
Keywords: anti-p200 pemphigoid, anti-laminin gamma-1 pemphigoid, IIF of salt-split skin, immunoblotting, ELISA, BMZ autoantibodies, mucosal disease, psoriasis
}

\section{INTRODUCTION}

Anti-p200 pemphigoid is a rare subepidermal autoimmune bullous disease (AIBD) initially described in $1996(1,2)$. This novel disease, presumed to be a subset of pemphigoid, was characterized by autoantibodies targeting a $200-\mathrm{kDa}$ protein localized within the lower lamina lucida of the basement membrane zone (BMZ). Their sera bound to the dermal side of salt-split skin by indirect immunofluorescence (IIF) microscopy (3). Subsequent studies demonstrated that sera from $90 \%$ of anti-p200 pemphigoid patients recognized laminin $\gamma 1$, which C-terminus was identified as an immunodominant region and utilized for immunoblotting and ELISA for diagnosis $(4,5)$. In outstanding research by German and Japanese investigators, using human foreskin and various mouse strains, the investigators clearly demonstrated that autoantibodies in anti-p200 pemphigoid sera are pathogenic, but their pathogenicity is not entirely mediated by autoantibodies against laminin $\gamma 1$. The specific or precise role for laminin $\gamma 1$ in pathogenesis requires further study, as ex vivo and in vivo studies did not show evidence of a direct pathogenic role of anti-laminin $\gamma 1$ antibodies, leaving the true molecular identity of the pathogenic $200 \mathrm{kDa}$ autoantigen yet to be 
fully characterized $(6,7)$. To elaborate, in two different mouse animal models for anti-laminin $\gamma 1$ pemphigoid, although murine IgG of the recombinant laminin $\gamma 1 \mathrm{C}$-terminus bound to the epidermal basement membrane zone in the passive transfer model, no obvious blister formation was seen (7). In an earlier ex vivo model of autoantibody-mediated leukocyte-dependent neutrophil activation, human and rabbit IgG from the Cterminus of laminin $\gamma 1$ failed to attract neutrophils at the dermal-epidermal-junction and to induce dermal-epidermal separation (6).

The clinical presentation of anti-p200 is polymorphic and may mimic bullous pemphigoid (BP), mucous membrane pemphigoid (MMP), and other subepidermal AIBD (8). However, data on its morphological features and the clinical course are limited, primarily because of the small number of reported cases and the lack of a large cohort of patients studied in detail with long-term follow-up.

We did not focus on therapy because it was considered beyond the scope of this analysis due to lack of uniformity, cohesive information, defined protocol, and outcome data. The aim of the current study was to perform a review of the available epidemiological, clinical, histological, and immunopathological data and the major comorbidities in patients with anti-p200 pemphigoid. The purpose was to help clinicians recognize this newly described clinical entity. This could result in early therapy and better prognosis.

\section{MATERIALS AND METHODS}

\section{Data Collection}

The literature review was conducted using Ovid-Medline (1946present), Embase (1947-present), and Web of Science (1900present) to identify eligible articles. Publications until August 9th 2018, were searched. The search strategies are detailed in Supplementary Table 1.

\section{Selection of Articles}

All publications reporting on one or multiple cases of anti-p200 pemphigoid were included. All cases were defined by the authors of the respective publications as anti-p200 pemphigoid based on the following three mandatory criteria: (i) clinical profile suggestive of subepidermal AIBD; (ii) reactivity to the $200 \mathrm{kDa}$ protein or to the recombinant C-terminus of laminin $\gamma 1$ by immunoblot analysis; and (iii) exclusion of other subepidermal AIBDs. Additionally, at least one of the following two minor criteria was required to establish the diagnosis of anti-p200 pemphigoid: (i) subepidermal cleft on histology; (ii) and direct immunofluorescence (DIF), demonstrating linear deposition of IgG and/or C3. Publications lacking these criteria were excluded.

\section{Data Extraction}

The following information was obtained when authors provided it: age at onset, sex, ethnicity, morphological features of the mucocutaneous manifestation and their anatomic distribution, histopathology, immunopathology, comorbidities, and triggering factors (if known). All statistical analysis was performed using SPSS software, version 23 (SPSS, Chicago, IL, USA).
TABLE 1 | Demographic characteristics of the patients reported with anti-p200 pemphigoid.

\begin{tabular}{|c|c|}
\hline Male patients, $n(\%)$ & $85(75.2 \%)$ \\
\hline \multicolumn{2}{|l|}{ Age at diagnosis } \\
\hline Mean $( \pm S D)^{*}$ & $65.5(15.9)$ \\
\hline Median (range) & $69(5-94)$ \\
\hline Mean age of male patients $( \pm S D)^{\star}$ & $66.0(14.0)$ \\
\hline Mean age of female patients $( \pm S D)^{\star}$ & $63.4(20.8)$ \\
\hline \multicolumn{2}{|l|}{ Ethnicity of reported patients, $n(\%)$} \\
\hline Asian & $57(50.4 \%)$ \\
\hline Caucasians & $22(19.5 \%)$ \\
\hline Jews & $1(0.9 \%)$ \\
\hline African American & $1(0.9 \%)$ \\
\hline Not reported & $32(28.3 \%)$ \\
\hline \multicolumn{2}{|c|}{ Geographical distribution of reported cases, \% (n) } \\
\hline Japan & $50(44.2 \%)$ \\
\hline France & $18(15.9 \%)$ \\
\hline Germany & $13(11.5 \%)$ \\
\hline Netherlands & $12(10.6 \%)$ \\
\hline USA & 7 (6.2\%) \\
\hline India & $3(2.7)$ \\
\hline Poland & $2(1.8 \%)$ \\
\hline Spain & $2(1.8 \%)$ \\
\hline China & 1 (0.9\%) \\
\hline UK & 1 (0.9\%) \\
\hline Israel & 1 (0.9\%) \\
\hline Croatia & 1 (0.9\%) \\
\hline Greece & 1 (0.9\%) \\
\hline Austria & 1 (0.9\%) \\
\hline Korea & $1(0.9 \%)$ \\
\hline
\end{tabular}

n, number; SD, standard deviation; USA, United States of America; UK, United Kingdom. "Excluding the study of Meijer et al. (3) which did not report standard deviation.

\section{RESULTS}

After a full-text review, 68 articles fulfilled the inclusion criteria, thereby providing 113 patients from 15 different countries that were included in the qualitative synthesis. Between 1996 and 2018, 50 cases (44.2\%) were reported from Japan (Table 1).

\section{Clinical Characteristics}

The mean age at onset was 65.5 years (range 5-94) $(9,10)$. The majority of the patients were males $(n=85 ; 75.2 \%)$ and of Asian ancestry $(n=57,50.4 \%$; Table $\mathbf{1})$.

The clinical presentation was described as resembling other subepidermal AIBD and inflammatory dermatoses by authors in $68(60.2 \%)$ patients. The leading similar condition was BP $(n=$ $45 ; 66.2 \%$ ), followed by linear IgA bullous dermatosis (LABD; $n=5 ; 7.4 \%)(9,11-14)$, epidermolysis bullosa acquisita (EBA; $n=3 ; 4.4 \%)(15-17)$, dermatitis herpetiformis ( $\mathrm{DH} ; n=3 ; 4.4 \%)$ (18-20), mucous membrane pemphigoid ( $n=3 ; 4.4 \%)(21-23)$, and others (Table 2 ). In the remaining 45 patients, a similarity to a distinct clinical entity was not mentioned. 
TABLE 2 | Clinical and morphological characteristics of the reported patients with anti-p200 pemphigoid.

\begin{tabular}{|c|c|c|}
\hline & & $\begin{array}{c}\text { Number of reported } \\
\text { cases }\end{array}$ \\
\hline \multicolumn{3}{|c|}{ Similar condition, $n(\%)-r e p o r t e d$ in 68 cases } \\
\hline Bullous pemphigoid & $45(66.2 \%)$ & 68 \\
\hline Linear IgA bullous dermatosis & $5(7.4 \%)$ & 68 \\
\hline Vesicular pemphigoid & $4(5.9 \%)$ & 68 \\
\hline Epidermolysis bullosa acquisita & $3(4.4 \%)$ & 68 \\
\hline Dermatitis herpetiformis & $3(4.4 \%)$ & 68 \\
\hline Mucous membrane pemphigoid & $3(4.4 \%)$ & 68 \\
\hline Erythema gyratum repens & $2(2.9 \%)$ & 68 \\
\hline Pemphigus & $1(1.5 \%)$ & 68 \\
\hline Pompholyx & $1(1.5 \%)$ & 68 \\
\hline \multicolumn{3}{|l|}{ Morphology of cutaneous lesions, $\boldsymbol{n}(\%)$} \\
\hline Bullae/vesicles & $113(100 \%)$ & 113 \\
\hline Urticarial plaques & $50(54.3 \%)$ & 92 \\
\hline Scars/milia & $16(15.7 \%)$ & 102 \\
\hline \multicolumn{3}{|c|}{ Anatomical distribution of cutaneous lesions, $n(\%)$} \\
\hline Extremities & $78(95.1 \%)$ & 82 \\
\hline Trunk & $58(70.7 \%)$ & 82 \\
\hline Palms and soles & $38(51.4 \%)$ & 74 \\
\hline Head and neck & $29(40.3 \%)$ & 72 \\
\hline Mucosal involvement & 37 (38.5\%) & 96 \\
\hline \multicolumn{3}{|l|}{ Mucosal involvement, $n$ (\%) } \\
\hline One mucosal surface & $29(30.2 \%)$ & 96 \\
\hline Two mucosal surfaces concomitantly & $6(6.3 \%)$ & 96 \\
\hline Three mucosal surfaces concomitantly & $2(2.1 \%)$ & 96 \\
\hline Oral mucosa & $31(32.3 \%)$ & 96 \\
\hline Anogenital mucosa & $12(12.5 \%)$ & 96 \\
\hline Conjunctival mucosa & $2(2.1 \%)$ & 96 \\
\hline
\end{tabular}

$n$, number. The right column represents the number of cases where the variable was reported or could be concluded. The ratios represent number of positive cases out of the number of reported cases.

All patients presented with bullae and/or vesicles, $54.3 \%$ (50/92) had urticarial plaques, $15.7 \%$ (16/102) had scars and/or milia (Table 2).

The distribution of cutaneous lesions was reported in 72 patients. The extremities were the most frequently involved (95.1\%), the trunk in $70.7 \%$, and palmoplantar and cephalic involvement in 51.4 and $40.3 \%$ of patients, respectively. Generalized involvement was reported in $41.5 \%$ of patients. Mucosal involvement was reported in $38.5 \%$ of patients, with the oral mucosa (32.3\%) being the most frequently involved. None of the patients had exclusively mucosal diseases (Table 2). Of great interest, the prevalence of mucosal involvement among Japanese patients $(22.5 \%)$ was significantly lower when compared to the remaining patients $(48.2 \% ; P<0.001)$.

\section{Histological Characteristics}

Histology data was available on 100 (88.5\%) patients. A subepidermal blistering was observed in all patients, along with mild to dense inflammatory infiltrates in the upper dermis
TABLE 3 | Immunopathological and immunological characteristics of the reported patients with anti-p200 pemphigoid.

Number of
reported cases

Direct immunofluorescence, $\boldsymbol{n}(\%)$

Linear deposition along the BMZ $\quad 113(100 \%)$

Linear deposition of $\operatorname{lgG}$ and C3 $\quad 77$ (78.6\%) 98

Linear deposition of IgG, IgA, and C3 $\quad 10(10.2 \%) \quad 98$

Linear deposition of C3 alone $\quad 4(4.1 \%) \quad 98$

Linear deposition of $\lg G$, IgA, IgM, and C3 $2(2.0 \%) \quad 98$

Linear deposition of IgG alone $\quad 2(2.0 \%) \quad 98$

$\mathrm{N}$-serration deposition pattern $\quad 11(84.6 \%) \quad 13$

U-serration deposition pattern $\quad 0(0 \%) \quad 13$

Undetermined deposition pattern $\quad 2(15.4 \%) \quad 13$

$\mathrm{NaCl}$-split indirect immunofluorescence deposition, $\boldsymbol{n}(\%)$

Dermal side $\quad 90(83.3 \%) \quad 108$

Both dermal and epidermal sides (more $16(14.8 \%)$

prominently in the dermal side)

$\begin{array}{lll}\text { Epidermal side } & 1(0.9 \%) & 108\end{array}$

$\begin{array}{lll}\text { Negative } & 1(0.9 \%) & 108\end{array}$

Immunoblot analysis, $\boldsymbol{n}(\%)$

200-kDa dermal protein $\quad 111(100 \%) \quad 111$

Recombinant C-terminus of laminin $\gamma 1 \quad 19(73.1 \%) \quad 26$

ELISA detecting recombinant monomeric $\mathrm{C}$-terminal fragment of human laminin $\gamma 1, n(\%)$

$10(100 \%)$

10

n, number; BMZ, basement membrane zone; Ig, immunoglobulin; ELISA, enzyme-linked immunosorbent assay. The right column represents the number of cases where the variable was reported or could be concluded. The ratios represent the number of positive cases out of the number of reported cases.

composed of neutrophils and eosinophils in 41 (41.0\%) and 15 (15.0\%) patients, respectively. A mixed infiltrate of neutrophils and eosinophils was seen in $40(40.0 \%)$ of patients. In two patients, an exclusively lymphocytic infiltrate was observed $(24,25)$; papillary microabscesses were observed in $11(11.0 \%)$ patients, a predominantly neutrophilic infiltrate in 10 patients $(2,14,18-20,26-29)$ and a mixed infiltrate in one patient (3). Eosinophilic spongiosis was observed in two patients $(3,27)$ and ruptured secondary milia with inflammatory granulomatous in one patient (16).

\section{Immunopathological Characteristics}

DIF microscopy of perilesional skin was reported in $98(88.1 \%)$ patients. Deposition of IgG and C3 was observed in 77 (78.6\%), whereas the simultaneous deposition of $\operatorname{IgG}, \operatorname{IgA}$, and C3 was observed in $10(10.2 \%)$ patients $(3,9,12,14,20,30)$. Deposition of IgG or C3 alone was observed in two (2.0\%) $(16,31)$ and four $(4.1 \%)$ patients $(22,32-34)$, respectively. $\mathrm{N}$-serration deposition pattern from a BMZ immunoreactant was shown in 11 of $13(84.6 \%)$ patients, whereas this pattern was undetermined in the remaining two (15.4\%) patients $(3,35,36)$ (Table 3).

On salt-split skin, binding to the dermal side of the split was reported in 90 patients $(83.3 \%)$ and binding to both the 
dermal and epidermal sides in 16 patients (14.8\%) (Table 3). Immunoblot analysis demonstrated reactivity to the $200 \mathrm{kDa}$ protein in all 111 patients tested using human dermal extract ( $n$ $=108)$, epidermal extracts $(n=11)(10,37)$ and keratinocytes extracts $(n=2)$ (32). Sera of several patients were tested on multiple extracts, and 10 of the 11 patients reacting to the epidermal extract were also seropositive on dermal extracts (10). In the remaining two patients, immunoblotting showed reactivity only to the recombinant C-terminus of laminin $\gamma 1(38,39)$. Of significant interest is that the sera of patients who were positive for antibodies when tested using immunoblot analysis with the recombinant C-terminus of laminin $\gamma 1$ was positive in 17 of 24 , with a $70.8 \%$ sensitivity $(3,9,31,38-43)$. Sera of 10 patients was tested by ELISA bound to a recombinant monomeric C-terminal fragment of human laminin $\gamma 1(10,44$, 45) (Table 3).

Autoantibodies targeting other antigens were detected in 20 (17.7\%). Autoantibodies against BP-180 alone, BP230 alone and both BP-180 and BP-230 were identified in two $(1.8 \%)(19,46)$, four $(3.5 \%)(2,36,47)$, and three $(2.7 \%)$ patients $(10,48)$, respectively. Antibodies to Type-VII collagen were found in three (2.7\%) patients $(15,16,49)$, whereas autoantibodies against different subunits of laminin 332 were detected in 7 (6.2\%) patients $(21,22,34,44,50-52)$.

\section{Associated Comorbidities}

An association with psoriasis was reported in 32 patients (28.3\%). Psoriasis preceded the diagnosis of anti-p200 pemphigoid in all patients by a mean of $15.1 \pm 10.4$ years (median, 18 years; range, 0.1-30 years). Four (12.5\%) patients had developed bullous disease with pustular psoriasis simultaneously $(33,35,53,54)$. The onset of anti-p200 pemphigoid was associated with erythrodermic psoriasis in one $(3.1 \%)$ patient $(55)$. The remaining patients $(84.4 \%)$ had psoriasis vulgaris. Of interest, $28(87.5 \%)$ patients with psoriasis were Japanese, whereas the remaining four (12.5\%) were Europeans (10, 27, 56, 57).

Taken together, the prevalence of psoriasis in antip200 pemphigoid Japanese patients was 56.0\% (95\% CI, $42.3-68.8 \%)$ as compared to only $6.4 \%$ (95\% CI, 2.5$15.2 \%)$ among non-Japanese patients $(P<0.001)$. There was a slightly higher frequency of males among antip200 pemphigoid patients with psoriasis compared to those without psoriasis ( 87.5 vs. $70.4 \% ; P=0.058)$. The age of presentation was comparable in the two subgroups (data not shown).

Concomitant malignancies were reported in three female patients. One had metastatic clear cell carcinoma of the ovary (21), one had uterine adenocarcinoma (58), and the other had metastatic esophageal adenocarcinoma (38). Other comorbidities reported included: end-stage kidney disease due to IgA nephropathy and glomerulonephritis $(n=2)(22,34)$, ulcerative colitis $(n=1)$ (50), esophagitis $(n=1)$ (15), polyarteritis nodosa $(n=1)(59)$, and autosomal recessive congenital ichthyosis $(n=1)$ (36). Unproven trigger factors included scabies $(n=2)(60,61)$ and use of penicillin $(n=1)(62)$.

\section{DISCUSSION}

This review highlights the multiple aspects of a recently described interesting subset of pemphigoid. Based on the current information, its main focus is the clinical features. Many of the unique characteristics and associations could be important to cutaneous biology and the pathogenesis of autoimmunity. A heterogeneous clinical profile that mimicked $\mathrm{BP}$ was present in the majority of patients, accompanied by a high prevalence of cephalic, palmoplantar and mucosal involvement. Autoantibodies against the recombinant C-terminus of laminin $\gamma 1$ were detected by immunoblotting in $73.1 \%$ of patients. The prevalence of coexistent psoriasis was significantly higher than in the general population. Interestingly, the presence of psoriasis was very significantly higher in Japanese than non-Japanese patients (56.0 vs. $6.4 \%$, respectively).

Palmoplantar lesions and mucosal involvement in $\mathrm{BP}$ has been reported in up to $20 \%$ of patients (63-65), and these regions were affected in 51.4 and $38.5 \%$ of patients with anti-p200 pemphigoid, respectively. Interestingly, scars and milia were reported in 3.4\% of patients with BP (63) but in $15.7 \%$ of patients with antip200 pemphigoid. In the clinical criteria suggested by Vaillant et al. (66), which yield a positive predictive value of $95 \%$ for a clinical diagnosis of BP, it is the absence of each of the three aforementioned features that has been identified as an independent predictive criterion for the diagnosis of BP.

The age at onset of patients with anti-p200 pemphigoid (65.5 years) is younger than many with BP, where it commonly occurs in those older than 70 (67-69). An overwhelming preponderance of males (75.2\%) were reported with anti-p200 pemphigoid, which contrasts with the female-to-male ratio ranges between 1.04 and 5.1 in different cohorts of BP (69).

In 2009, Dainichi et al. (4) found that $90 \%$ of sera tested from anti-p200 pemphigoid patients reacted to the C-terminus of recombinant laminin $\gamma 1$, using an immunoblot assay. This observation has been confirmed by Groth et al. (5). This analysis demonstrates that sera from $73.1 \%$ of the patients reported reacting to the $\mathrm{C}$-terminus of recombinant laminin $\gamma 1$ protein using the immunoblotting assay. With respect to the ELISA using a monomeric C-terminal fragment of human laminin, the sensitivity was estimated at $68.6 \%$ (5).

The incidence of anti-p200 pemphigoid is considerably low amongst AIBD (70). In a cohort of 145 Japanese patients with various AIBDs, anti-p200 pemphigoid was the second most prevalent AIBD (37.2\%). The prevalence of psoriasis among nonJapanese anti-p200 pemphigoid patients $(6.4 \%)$ was greater than its incidence in the general population of the world $(71,72)$. The pathomechanism of this ethnic association is yet to be established (70). Pustular psoriasis was present in $12.5 \%$ of $\mathrm{p}-200$ pemphigoid patients. This incidence is significantly higher than the $1.3 \%$ reported in a cohort of 104,669 patients with different variants of psoriasis $(P<0.001)(73)$. This observation confirmed an earlier Japanese study which reported that $53.8 \%$ of patients with pustular psoriasis and AIBD had anti-p200 pemphigoid (70). The molecular basis for this rare and unique combination of clinical entities has not been clearly defined and warrants attention. Senescence was suggested to alter the distribution and 
amount of proteins in the BMZ, thus increasing its antigenicity and raising the risk of the development of an autoimmune response against its components (74). Since the cell cycle and turnover of the epidermal keratinocytes are extremely accelerated in psoriasis, it was recently assumed that the extracellular matrix in psoriatic skin may simulate the senescent extracellular matrix and contribute to the development of BP and other AIBDs that were found to be associated with psoriasis (75).

Our current knowledge of anti-p-200 pemphigoid brings into focus several important and interesting issues. Traditionally, pemphigoid is divided into $\mathrm{BP}$ and mucous membrane pemphigoid. It is possible that because anti-p200 pemphigoid has certain features of both conditions, it could be the bridge or missing link between them. Some anti-p200 pemphigoid also has features of other AIBD, since their sera contain autoantibodies associated with them. It would be interesting to speculate whether this was due to epitope spreading (76). Patients with systemic lupus erythematosus have multiple pathogenic autoantibodies per patient (77), including multiple phenotypes and symptomatologies.

An additional unsolved question is whether anti-p-200 pemphigoid is truly rare or whether it is rather underdiagnosed worldwide. In the US, tests for detecting autoantibodies to laminin $\gamma 1$ are commercially unavailable, though they are available in Germany and Japan. Moreover, investigators in those countries, whose laboratories are equipped to perform these assays, provide them to their colleagues. The majority of patients are thus reported from Japan and Europe. Unless there are very specific unidentified reasons, there are generally no reasons to believe that it cannot not be as prevalent in other countries. Unless more patients are studied, serologically characterized and followed up for several years, this challenging variant of pemphigoid will remain less well-studied and understood. This would be tragic, because it could help advance our knowledge.

The main limitations of this review are that it was based on case reports and small case series and that it is retrospective. Some of the variables were not provided by some authors. Data on

\section{REFERENCES}

1. Zillikens D, Kawahara Y, Ishiko A, Shimizu H, Mayer J, Rank CV, et al. A novel subepidermal blistering disease with autoantibodies to a $200-\mathrm{kDa}$ antigen of the basement membrane zone. J Invest Dermatol. (1996) 106:1333-8. doi: 10.1111/1523-1747.ep12349283

2. Chen KR, Shimizu S, Miyakawa S, Ishiko A, Shimizu H, Hashimoto T. Coexistence of psoriasis and an unusual IgG-mediated subepidermal bullous dermatosis: identification of a novel 200-kDa lower lamina lucida target antigen. $\mathrm{Br} J$ Dermatol. (1996) 134:340-6. doi: 10.1111/j.1365-2133.1996.tb07625.x

3. Meijer JM, Diercks GFH, Schmidt E, Pas HH, Jonkman MF. Laboratory diagnosis and clinical profile of anti-p200 pemphigoid. JAMA Dermatol. (2016) 152:897-904. doi: 10.1001/jamadermatol.2016. 1099

4. Dainichi T, Kurono S, Ohyama B, Ishii N, Sanzen N, Hayashi M, et al. Antilaminin gamma-1 pemphigoid. Proc Natl Acad Sci USA. (2009) 106:2800-5. doi: 10.1073/pnas.0809230106

5. Groth S, Recke A, Vafia K, Ludwig RJ, Hashimoto T, Zillikens D, et al. Development of a simple enzyme-linked immunosorbent assay for the treatment were scarce, limited and not comprehensive. Limited follow-up did not provide a clear clinical course or an overview of the impact of treatment on clinical course. The universal lack of the ELISAs makes it impossible to assess its global presence. Since psoriasis is present universally, its relationship could not be accurately assessed.

In conclusion, this new subset provides, to clinicians and scientists alike, a unique opportunity to study several new frontiers of cutaneous biology, inflammation, immunology, scar formation and disease pathogenesis. The location of laminin $\gamma 1$ provides the opportunity to study interactions amongst other BMZ proteins. An association with psoriasis provides a playground to study what influences neutrophils to cause different pathologies and clinical profiles. The presence of scarring in mucosal tissues of some patients and not in others could provide important leads into what thrusts patients into one direction or the other. This opportunity, provided by nature, should not be missed but utilized to the advantage of our patients and the progress of our specialty.

\section{AUTHOR CONTRIBUTIONS}

AA and KK contributed to the concept, content, and writing of the manuscript.

\section{FUNDING}

This study was supported in part by an unrestricted educational grant from the Dysimmune Diseases Foundation, Panama City, FL, USA.

\section{SUPPLEMENTARY MATERIAL}

The Supplementary Material for this article can be found online at: https://www.frontiersin.org/articles/10.3389/fimmu. 2019.02466/full\#supplementary-material detection of autoantibodies in anti-p200 pemphigoid. Br J Dermatol. (2011) 164:76-82. doi: 10.1111/j.1365-2133.2010.10056.x

6. Vafia K, Groth S, Beckmann T, Hirose M, Dworschak J, Recke A, et al. Pathogenicity of autoantibodies in anti-p200 pemphigoid. PLoS ONE. (2012) 7:e41769. doi: 10.1371/journal.pone.0041769

7. Koga H, Ishii N, Dainichi T, Tsuruta D, Hamada T, Ohata C, et al. An attempt to develop mouse model for anti-laminin gamma 1 pemphigoid. J Dermatol Sci. (2013) 70:108-15. doi: 10.1016/j.jdermsci.2013.01.001

8. Goletz S, Hashimoto T, Zillikens D, Schmidt E. Anti-p200 pemphigoid. J Am Acad Dermatol. (2014) 71:185-91. doi: 10.1016/j.jaad.2014.02.036

9. Patsatsi A, Meltzanidou P, Katafigiotis S, Sotiriadis D, Schmidt E, Lambropoulos A. Chronic bullous disease of childhood with IgG reactivity to p200 antigen. Int J Dermatol. (2017) 56:773-5. doi: 10.1111/ijd.13616

10. Commin MH, Schmidt E, Duvert-Lehembre S, Lasek A, Morice C, Estival JL, et al. Clinical and immunological features and outcome of anti-p200 pemphigoid. Br J Dermatol. (2016) 175:776-81. doi: 10.1111/bjd.14629

11. Myers DJ, Unwala RD, Xia L, Groth S, Zillikens D, Stratman EJ. Generalized annular bullous eruption-quiz case. Anti-laminin gammal pemphigoid with a linear IgA bullous dermatosis-like presentation. Arch Dermatol. (2011) 147:109-14. doi: 10.1001/archdermatol.2010.404-a 
12. Kawahara Y, Matsuo Y, Hashimoto T, Nishikawa T. A case of unique subepidermal blistering disease with autoantibodies against a novel dermal 200-kD antigen. Dermatology. (1998) 196:213-6. doi: 10.1159/000017901

13. Goto-Ohguchi Y, Nishie W, Akiyama M, Tateishi Y, Aoyagi S, Tsuji-Abe $\mathrm{Y}$, et al. A severe and refractory case of anti-p200 pemphigoid resulting in multiple skin ulcers and scar formation. Dermatology. (2009) 218:265-71. doi: $10.1159 / 000182268$

14. Watanabe M, Tsunoda T, Tagami H. A subepidermal blistering dermatosis associated with coexistent IgG and IgA anti-dermal basement membrane zone antibodies; demonstration of IgG antibodies reactive against a $200-\mathrm{kDa}$ dermal antigen. Eur J Dermatol. (2002) 12:603-6.

15. Yamada T, Suzuki M, Koike Y, Kida K, Murata S, Ishii N, et al. A case of epidermolysis bullosa acquisita with autoantibody to anti-p200 pemphigoid antigen and exfoliative esophagitis. Dermatology. (2006) 212:3814. doi: 10.1159/000092292

16. Pastar Z, Rados J, Lipozencic J, Dobric I, Marinovic B, Ishii N, et al. Case of concurrent epidermolysis bullosa acquisita and antip200 pemphigoid - How to treat it? Int J Dermatol. (2007) 46:295-8. doi: 10.1111/j.1365-4632.2006.02969.x

17. Umemoto N, Demitsu T, Toda S, Noguchi T, Suzuki SI, Kakurai M, et al. A case of anti-p200 pemphigoid clinically mimicking inflammatory epidermolysis bullosa acquisita [1]. Br J Dermatol. (2003) 148:1058-60. doi: 10.1046/j.1365-2133.2003.05312.x

18. Wozniak K, Hashimoto T, Fukuda S, Ohyama B, Ishii N, Koga H, et al. IgA anti-p200 pemphigoid. Arch Dermatol. (2011) 147:1306-10. doi: 10.1001/archdermatol.2011.303

19. Salmhofer W, Kawahara Y, Soyer HP, Kerl H, Nishikawa T, Hashimoto T. A subepidermal blistering disease with histopathological features of dermatitis herpetiformis and immunofluorescence characteristics of bullous pemphigoid: a novel subepidermal blistering disease or a variant of bullous pemphigoid? Br J Dermatol. (1997) 137:599-604. doi: 10.1111/j.1365-2133.1997.tb03794.x

20. Yasuda H, Tomita Y, Shibaki A, Hashimoto T. Two cases of subepidermal blistering disease with anti-p200 or 180-kd bullous pemphigoid antigen associated with psoriasis. Dermatology. (2004) 209:149-55. doi: $10.1159 / 000079602$

21. Mitsuya J, Hara H, Ito K, Ishii N, Hashimoto T, Terui T. Metastatic ovarian carcinoma-associated subepidermal blistering disease with autoantibodies to both the p200 dermal antigen and the $\gamma 2$ subunit of laminin 5 showing unusual clinical features. Br J Dermatol. (2008) 158:1354-7. doi: 10.1111/j.1365-2133.2008.08483.x

22. Mitate E, Kawano S, Nakao Y, Goto Y, Kobayashi I, Onozawa K, et al. Concurrence of autoantibodies to both laminin $\gamma 1$ and $\gamma_{2}$ subunits in a patient with kidney rejection response. Acta Derm Venereol. (2013) 93:114-5. doi: 10.2340/00015555-1395

23. Zhiliang L, Xiaodong Z, Peiying J, Suying F, Baoxi W. A case of refractory antilaminin $\gamma 1$ pemphigoid successfully treated with dexamethasone and mycophenolate mofetil. Int J Dermatol. (2015) 54:e194-6. doi: 10.1111/ijd.12763

24. Waki Y, Kamiya K, Komine M, Maekawa T, Murata S, Ishii N, et al. A case of anti-laminin gammal (p200) pemphigoid with psoriasis vulgaris successfully treated with apremilast. Eur J Dermatol. (2018) 28:413-4. doi: 10.1684/ejd.2018.3280

25. Majima Y, Yagi H, Tateishi C, Groth S, Schmidt E, Zillikens D, et al. A successful treatment with ustekinumab in a case of antilaminin-gammal pemphigoid associated with psoriasis. Br J Dermatol. (2013) 168:1367-9. doi: $10.1111 /$ bjd. 12163

26. Mascaro JMJ, Zillikens D, Giudice GJ, Caux F, Fleming MG, Katz HM, et al. A subepidermal bullous eruption associated with IgG autoantibodies to a $200 \mathrm{kd}$ dermal antigen: the first case report from the United States. J Am Acad Dermatol. (2000) 42:309-15. doi: 10.1016/S0190-9622(00) 90101-4

27. García-Díez I, Martínez-Escala ME, Ishii N, Hashimoto T, Mascaró Galy JM, Pujol RM, et al. Usefulness of a simple immunohistochemical staining technique to differentiate anti-p200 pemphigoid from other autoimmune blistering diseases: a report of 2 cases. Actas Dermosifiliogr. (2016) 108:e1-5. doi: 10.1016/j.adengl.2016.11.018
28. Rose C, Weyers W, Denisjuk N, Hillen U, Zillikens D, Shimanovich I. Histopathology of anti-p200 pemphigoid. Am J Dermatopathol. (2007) 29:119-24. doi: 10.1097/DAD.0b013e31803326e6

29. Egan CA, Yee C, Zillikens D, Yancey KB. Anti-p200 pemphigoid: diagnosis and treatment of a case presenting as an inflammatory subepidermal blistering disease. J Am Acad Dermatol. (2002) 46:786-9. doi: 10.1067/mjd.2002.120923

30. Kingsbery MY, Grossman ME, Nguyen H. Consider antilaminin gamma-1 pemphigoid when faced with conflicting histopathology and immunofluorescence results. J Am Acad Dermatol. (2013) 68:e60-1. doi: 10.1016/j.jaad.2012.08.038

31. Iikawa M, Muroi E, Ishii Y, Mochid AK, Setoyama M, Kurokawa M, et al. A case of anti-laminin gamma; 1 pemphigoid with cutaneous polyarteritis nodosa. Nishi Nihon Hifuka. (2013) 75:7-10. doi: 10.2336/nishinihonhifu.75.7

32. Hofmann SC, Voith U, Sasaki TS, Trueeb RM, Nischt RN, BrucknerTuderman L. Evidence for synthesis of p200, the autoantigen in anti-p200 pemphigoid, by keratinocytes and fibroblasts. J Invest Dermatol. (2007) 127:S73. doi: $10.1038 /$ sj.jid.5700952

33. Miyakura T, Yamamoto T, Tashiro A, Okubo Y, Oyama B, Ishii N, et al. Anti-p200 pemphigoid associated with annular pustular psoriasis. Eur J Dermatology. (2008) 18:481-2. doi: 10.1684/ejd.2008.0465

34. Kamata M, Fujita H, Hamanaka T, Takahashi K, Koga H, Hashimoto T, et al. Anti-laminin gammal pemphigoid accompanied by autoantibodies to laminin alpha3 and gamma2 subunits of laminin-332. JAMA Dermatol. (2013) 149:1437-9. doi: 10.1001/jamadermatol.2013.5358

35. Igarashi M, Tsunemi Y, Koga H, Hashimoto T, Tateishi C, Tsuruta D, et al. Anti-laminin gammal pemphigoid associated with pustular psoriasis. Eur J Dermatol. (2014) 24:629-30. doi: 10.1684/ejd.2014.2419

36. Ohzone A, Numata S, Hamada T, Fukuda S, Teye K, Shirakashi Y, et al. Anti-laminin-gamma 1 pemphigoid developed in a case of autosomal recessive congenital ichthyosis. Acta Derm Venereol. (2015) 95:93-4. doi: 10.2340/00015555-1875

37. Munsch C, Prey S, Joly P, Meyer N, Lamant L, Livideanu C, et al. [Anti-p200 pemphigoid: a spectacular response to dapsone]. Ann Dermatol Venereol. (2011) 138:739-42. doi: 10.1016/j.annder.2011.05.024

38. Goetze S, Dumke A-K, Zillikens D, Hipler UC, Elsner P. Anti-p200/laminin gammal pemphigoid associated with metastatic oesophageal cancer. J Eur Acad Dermatol Venereol. (2017) 31:e219-21. doi: 10.1111/jdv. 13983

39. Tatsumi M, Kamei R, Nakai D, Mabuchi E, Ikegami E, Fukuda S, et al. Complicated case of anti-laminin gamma-1 pemphigoid in psoriasis. Ski Res. (2012) 11:75-81. doi: 10.11340/skinresearch.11.1 75

40. McCarty M, Zillikens D, Fivenson D. Anti-p200 pemphigoid (anti-laminingammal pemphigoid) demonstrating pathergy. Int J Women Dermatol. (2015) 1:173-4. doi: 10.1016/j.ijwd.2015.09.002

41. Alloo A, Strazzula L, Rothschild B, Hawryluk E, Levine D, Hoang MP, et al. Refractory antilaminin $\gamma 1$ pemphigoid successfully treated with intravenous immunoglobulin and mycophenolate mofetil. J Eur Acad Dermatology Venereol. (2014) 28:1401-3. doi: 10.1111/jdv.12352

42. Goyal N, Rao R, Shenoi S, Pai S, Kumar P, Bhogal B, et al. Epidermolysis bullosa acquisita and anti-p200 pemphigoid as major subepidermal autoimmune bullous diseases diagnosed by floor binding on indirect immunofluorescence microscopy using human salt-split skin. Indian J Dermatol Venereol Leprol. (2017) 83:550-5. doi: 10.4103/ijdvl.IJDVL_678_16

43. Geller S, Gat A, Zeeli T, Schmidt E, Ishii N, Hashimoto T, et al. A refractory, cutaneous, subepidermal bullous disease. Clin Exp Dermatol. (2016) 41:573-5. doi: $10.1111 /$ ced. 12823

44. Monshi B, Groth S, Richter L, Schmidt E, Zillikens D, Rappersberger K. A long-term study of a patient with anti-p200 pemphigoid: correlation of autoantibody levels with disease activity and an example of epitope spreading. Br J Dermatol. (2012) 167:1179-83. doi: 10.1111/j.1365-2133.2012. 11076.x

45. Ishida S, Takahashi K, Kanaoka M, Okawa T, Tateishi C, Yasukochi A, et al. Case of subepidermal autoimmune bullous disease with psoriasis vulgaris reacting to both BP180 C-terminal domain and laminin gamma-1. J Dermatol. (2015) 42:391-3. doi: 10.1111/1346-8138.12801

46. Ansai S-I, Hashizume S, Kawana S, Tateishi C, Koga H, Hashimoto T. Case of anti-laminin gamma-1 pemphigoid with antibody against C-terminal domain 
of BP180 in a patient with psoriasis vulgaris. J Dermatol. (2014) 41:1031-3. doi: 10.1111/1346-8138.12625

47. Kawahara Y, Zillikens D, Yancey KB, Marinkovich MP, Nie Z, Hashimoto $\mathrm{T}$, et al. Subepidermal blistering disease with autoantibodies against a novel dermal 200-kDa antigen. J Dermatol Sci. (2000) 23:93-102. doi: 10.1016/S0923-1811(99)00093-6

48. Imanishi A, Tateishi C, Imanishi H, Sowa-Osako J, Koga H, Tsuruta D, et al. Pemphigoid with antibodies to laminin gamma 1, BP180 and BP230, associated with psoriasis vulgaris: Successful disease control with cyclosporin. J Dermatol. (2015) 42:394-7. doi: 10.1111/1346-8138.12798

49. Furukawa H, Miura T, Takahashi M, Nakamura K, Kaneko F, Ishii F, et al. A case of anti-p200 pemphigoid with autoantibodies against both a novel 200$\mathrm{kD}$ dermal antigen and the $290-\mathrm{kD}$ epidermolysis bullosa acquisita antigen. Dermatology. (2004) 209:145-8. doi: 10.1159/000079601

50. Akasaka E, Nakano H, Korekawa A, Fukui T, Kaneko T, Koga H, et al. Antilaminin $\gamma 1$ pemphigoid associated with ulcerative colitis and psoriasis vulgaris showing autoantibodies to laminin $\gamma 1$, type XVII collagen and laminin-332. Eur J Dermatol. (2015) 25:198-9. doi: 10.1684/ejd.2014.2499

51. Shimanovich I, Petersen EE, Weyers W, Sitaru C, Zillikens D. Subepidermal blistering disease with autoantibodies to both the p200 autoantigen and the alpha3 chain of laminin 5. (2005) 52:S90-2. doi: 10.1016/j.jaad.2004.07.036

52. Li X, Qian H, Ishii N, Yamaya M, Fukuda H, Mukai H, et al. A case of concurrent antilaminin gamma 1 pemphigoid and antilaminin-332type mucous membrane pemphigoid. Br J Dermatol. (2014) 171:1257-9. doi: $10.1111 /$ bjd.13107

53. Fujimura Y, Natsuga K, Hamade Y, Nomura Y, Kaku Y, Muramatsu $\mathrm{R}$, et al. Anti-laminin-gamma 1 pemphigoid with generalized pustular psoriasis and psoriasis vulgaris. Acta Derm Venereol. (2016) 96:120-1. doi: 10.2340/00015555-2168

54. Saeki H, Hayashi N, Komine M, Soma Y, Shimada S, Watanabe K, et al. A case of generalized pustular psoriasis followed by bullous disease: an atypical case of bullous pemphigoid or a novel bullous disease? Br J Dermatol. (1996) 134:152-5. doi: 10.1046/j.1365-2133.1996.d01-758.x

55. Kaminaka C, Kanazawa N, Furukawa F, Hashimoto T. Case of anti-laminin$\gamma 1$ pemphigoid associated with psoriatic erythroderma. J Dermatol. (2010) 37:272-5. doi: 10.1111/j.1346-8138.2009.00790.x

56. Morris SD, Mallipeddi R, Oyama N, Gratian MJ, Harman KE, Bhogal BS, et al. Psoriasis bullosa acquisita. Clin Exp Dermatol. (2002) 27:665-9. doi: 10.1046/j.1365-2230.2002.01100.x

57. Gawaz A, Metzler G, Hertl M, Hashimoto T, Schaller M. Treatment of antilaminin $\gamma 1$ pemphigoid with mycophenolate mofetil. J Dtsch Dermatol Ges. (2015) 13:696-7. doi: 10.1111/ddg.12564

58. Hayashi M, Okamura K, Ujiie H, Iwata H, Suzuki T. Case of anti-p200 pemphigoid accompanying uterine malignancy. J Dermatol. (2018) 45:e341-2. doi: $10.1111 / 1346-8138.14473$

59. Mai Y, Nishie W, Izumi K, Toyonaga E, Ikawa $H$, Mori $T$, et al. Detection of major epitopes for autoantibodies in dipeptidyl peptidase IV inhibitors-associated bullous pemphigoid. J Invest Dermatol. (2018) 138:S53. doi: 10.1016/j.jid.2018.03.319

60. Iijima S, Okazaki Y, Watanabe S, Tsuruta D, Tateishi C, Ishii N, et al. Case of concurrence of anti-laminin gamma-1 pemphigoid and scabies. J Dermatol. (2015) 42:1024-6. doi: 10.1111/1346-8138.13020

61. Ogata M, Misago N, Inoue T, Hirashima N, Narisawa Y, Ishii N, et al. A case of anti-p200 pemphigoid-discussion of association with scabies. Nishi Nihon Hifuka. (2006) 68:375-9. doi: 10.2336/nishinihonhifu.68.375

62. Wozniak K, Kowalewski C, Hashimoto T, Ishii N, GlinskaWielochowska M, Schwartz RA. Penicillin-induced anti-p200 pemphigoid: an unusual morphology. Acta Derm Venereol. (2006) 86:443-6. doi: 10.2340/00015555-0117

63. Della Torre R, Combescure C, Cortés B, Marazza G, Beltraminelli H, Naldi $\mathrm{L}$, et al. Clinical presentation and diagnostic delay in bullous pemphigoid: a prospective nationwide cohort. Br J Dermatol. (2012) 167:1111-7. doi: 10.1111/j.1365-2133.2012.11108.x

64. Clapé A, Muller C, Gatouillat G, Le Jan S, Barbe C, Pham B-N, et al. Mucosal involvement in bullous pemphigoid is mostly associated with disease severity and to absence of anti-BP230 autoantibody. Front Immunol. (2018) 9:479. doi: 10.3389/fimmu.2018.00479

65. Di Zenzo G, Thoma-Uszynski S, Fontao L, Calabresi V, Hofmann SC, Hellmark T, et al. Multicenter prospective study of the humoral autoimmune response in bullous pemphigoid. Clin Immunol. (2008) 128:41526. doi: 10.1016/j.clim.2008.04.012

66. Vaillant L, Bernard P, Joly P, Prost C, Labeille B, Bedane C, et al Evaluation of clinical criteria for diagnosis of bullous pemphigoid. French Bullous Study Group. Arch Dermatol. (1998) 134:1075-80. doi: 10.1001/archderm.134.9.1075

67. Joly P, Baricault S, Sparsa A, Bernard P, Bédane C, Duvert-Lehembre S, et al. Incidence and mortality of bullous pemphigoid in France. J Invest Dermatol. (2012) 132:1998-2004. doi: 10.1038/jid.2012.35

68. Kridin K, Bergman R. Ethnic variations in the epidemiology of bullous pemphigoid in Israel. Int J Dermatol. (2017) 57:34-9. doi: 10.1111/ijd.13813

69. Kridin K. Subepidermal autoimmune bullous diseases: overview, epidemiology, and associations. Immunol Res. (2018) 66:6-17. doi: 10.1007/s12026-017-8975-2

70. Ohata C, Ishii N, Koga H, Fukuda S, Tateishi C, Tsuruta D, et al. Coexistence of autoimmune bullous diseases (AIBDs) and psoriasis: a series of 145 cases. J Am Acad Dermatol. (2015) 73:50-5. doi: 10.1016/j.jaad.2015. 03.016

71. Michalek IM, Loring B, John SM. A systematic review of worldwide epidemiology of psoriasis. J Eur Acad Dermatol Venereol. (2017) 31:205-12. doi: $10.1111 /$ jdv. 13854

72. Parisi R, Symmons DPM, Griffiths CEM, Ashcroft DM. Global epidemiology of psoriasis: a systematic review of incidence and prevalence. J Invest Dermatol. (2012) 133:377-85. doi: 10.1038/jid.20 12.339

73. Takahashi H, Nakamura K, Kaneko F, Nakagawa $H$, Iizuka $H$. Analysis of psoriasis patients registered with the Japanese Society for Psoriasis Research from 2002-2008. J Dermatol. (2011) 38:1125-9. doi: 10.1111/j.1346-8138.2010.01145.x

74. Watanabe M, Natsuga K, Nishie W, Kobayashi Y, Donati G, Suzuki S, et al. Type XVII collagen coordinates proliferation in the interfollicular epidermis. Elife. (2017) 6:e26635. doi: 10.7554/eLife.26635

75. Dainichi T, Kabashima K. Interaction of psoriasis and bullous diseases. Front Med. (2018) 5:222. doi: 10.3389/fmed.2018.00222

76. Chan LS, Vanderlugt CJ, Hashimoto T, Nishikawa T, Zone JJ, Black $\mathrm{MM}$, et al. Epitope spreading: lessons from autoimmune skin diseases. J Invest Dermatol. (1998) 110:103-9. doi: 10.1046/j.1523-1747.1998. 00107.x

77. Ippolito A, Wallace DJ, Gladman D, Fortin PR, Urowitz M, Werth V, et al. Autoantibodies in systemic lupus erythematosus: comparison of historical and current assessment of seropositivity. Lupus. (2011) 20:250-5. doi: $10.1177 / 0961203310385738$

Conflict of Interest: The authors declare that the research was conducted in the absence of any commercial or financial relationships that could be construed as a potential conflict of interest.

Copyright (c) 2019 Kridin and Ahmed. This is an open-access article distributed under the terms of the Creative Commons Attribution License (CC BY). The use, distribution or reproduction in other forums is permitted, provided the original author(s) and the copyright owner(s) are credited and that the original publication in this journal is cited, in accordance with accepted academic practice. No use, distribution or reproduction is permitted which does not comply with these terms. 